\title{
Daphnia and ciliates: who is the prey?
}

\author{
Marina MANCA*, Cristiana CALLIERI and Antonella CATTANEO ${ }^{1)}$ \\ CNR Institute of Ecosystem Study, L.go V. Tonolli 50, 28922 Verbania Pallanza, Italy \\ ${ }^{1)}$ Departement de Sciences Biologiques, Université de Montreal, C.P. 6128, Succ. Centre Ville, Montreal, Quebec, Canada H3C 3J7 \\ *e-mail corresponding author: m.manca@ise.cnr.it
}

\begin{abstract}
The fortuitous observation of a Daphnia infested by Gymnostomatida led us to hypothesize that egg predation by ciliates could be an important mechanism regulating cladoceran population dynamics. In light of this hypothesis we reanalysed data on the dynamics of Daphnia eggs and of one Gymnostomatida species from Lago Maggiore (1996). This communication is mainly a plea to examine data where both cladocerans and Gymnostomatida were collected, to verify if the occurrence of this yet undescribed eggvoricity is widespread. Further research is needed to investigate the ecological significance of this phenomenon.
\end{abstract}

Key words: Daphnia, ciliates, eggvoricity

\section{A FORTUITOUS OBSERVATION}

According to the accepted paradigma of the microbial food web, ciliates feed on bacteria, algae, and other protozoans (Fenchel 1987; Porter 1996) and are eaten by zooplankton (Sanders \& Wickham 1993). There are several reviews of metazoan-protozoan interactions in marine and freshwater ecosystems (Stoecker \& Capuzzo 1990; Arndt 1993). In particular, Jürgens (1994) has reviewed the evidence of a top-down control by Daphnia on protozoans, especially ciliates, both in natural and in experimental systems.

Beside these prey-predator relationships, parasitism and symbiosis have been described between ciliates and several freshwater organisms like perch (Nikolic \& Simonovic 1996), crayfish (Edgerton et al. 1996), zebra mussels (Molloy et al. 1996; Laruelle et al. 1999), and chironomids (Golini \& Corliss 1981).

We report here the fortuitous observation of a $D$. hyalina individual, which was heavily infested by ciliates of the order Gymnostomatida (Fig. 1). This individual was from a clone (DH7, kindly provided by NIOO, Nieuwersluis, The Netherlands) maintained in lake water (Lago Maggiore) enriched with Scenedesmus obliquus for laboratory experiments. The presence in the brood chamber of oil drops typically found in eggs and embryos suggested that eggs or embryos were present before the infestation. The oil drops might represent the remains of degenerated or viable eggs under development (Z.M. Gliwicz, Warsaw, pers. comm.) consumed by the ciliates. After renewal of the culture medium, the infestation declined and the female survived, although remaining eggless for approximately a week.

Our finding could represent a not yet described type of eggvoricity within zooplanktonic organisms, which may be of some interest for analyses of trophic interactions.

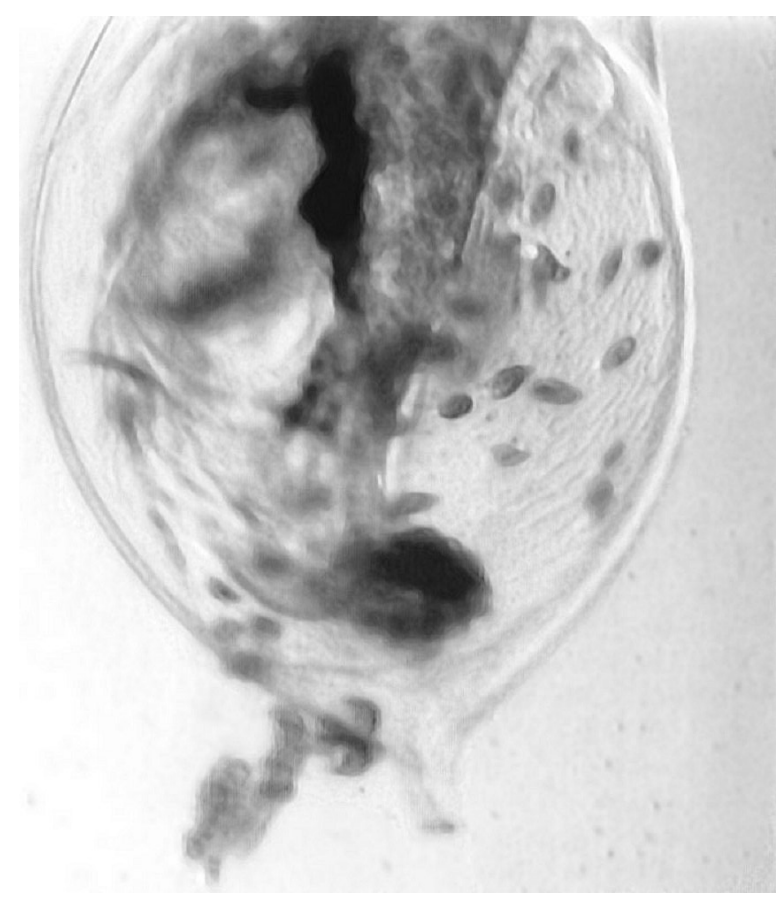

Fig. 1. A D. hyalina individual heavily infested by ciliates of the order Gymnostomatida. This individual was from clone DH7, kindly provided by NIOO, Nieuwersluis, The Netherlands.

First observed by Dziuban (1939), zooplankton eggvoricity, particularly the ability of cyclopoid copepods to feed on fish eggs, was overlooked for a long time. Because most early studies were directed toward describing and measuring the predation rate of adult cyclopoids and the ability of immature stages to utilize 
different types and sizes of particles, the finding of copepodites within the Daphnia brood chamber was long regarded as an artefact (Green 1974). Eggvoricity, particularly on Daphnia eggs or embryos, has been recently re-evaluated as the expression of a true food preference (Gliwicz \& Stibor 1993; Gliwicz 1994; Gliwicz \& Lampert 1994; Gliwicz \& Umana 1994) that is not restricted to cyclopoids, but occurs also in some calanoids. Because large cladocerans $(>2.25 \mathrm{~mm}$ body length, from the apex of the eye to the base of the tail spine) are selected by small copepodites, this eggvoricity is a peculiar type of size-selective invertebrate predation. The prey size spectrum of this predation overlaps with that of zooplanktivorous fish. However, the two forms of predation differ because only the latter is fatal for the prey. The subtraction of eggs and embryos from the mother's brood pouch leads to a depression of population density and fecundity. The pattern produced is similar to that usually ascribed to food shortage, although its different origin may be detected through an analysis of size-specific fecundity, since only large mothers' fecundity would be affected (Gliwicz \& Boavida 1996).

Beside copepods, other organisms have been reported to infest zooplankton eggs. Chatton (1920) in his monograph on parasitic peridinians reported that some species of Oodinium are parasites of copepods' eggs. Green (1974) reported a coccoid bacterium parasite in Daphnia eggs, as well as the microsporid protozoa Plistophora schaefernai Jirovec infecting developing Daphnia's oocytes. Because ciliates can be histophagous and feed on live, but often damaged animal tissues (Fenchel 1987), it is plausible to hypothesize their consumption of eggs especially the non-viable ones. To our knowledge, the only other example in which ciliates interfere on egg production is the parasitism of ovaries of a mosquito (Aedes sierrensis) by Lambornella clarki (Egerter et al. 1986). The ciliate infects the aquatic larva and then multiplies in the ovaries of the adult females: this parasitic castration has implications for mosquito biological control.

Our observation of a Daphnia infested by ciliates offers an opportunity to discuss the possible consumption of Daphnia eggs by organisms other than copepods. Consumption of eggs by ciliates would deprive mothers, partially or completely, of their broods. Partial consumption could lead to a decline in population fecundity whereas complete consumption could decrease the proportion of adults with eggs. Being not size-specific, this decrease in fecundity would completely mimic the effect of food shortage. This mechanism would be very difficult to detect by inspection of fixed samples, because oil drops are quickly lost from the mother's brood pouch upon fixation. Affecting the mortality of eggs and embryos without killing the mothers, the consumption of Daphnia eggs by ciliates would also mimic the effect of invertebrate predation. Following the com- mon methods used in population dynamics, consumed eggs might be interpreted as a case of mortality of the young stages, typically brought about by size-selective invertebrate predation.

\section{A POSSIBLE INTERPRETATION}

Data from Lago Maggiore (North Italy) provide a good example of how Daphnia population dynamics could be interpreted in different ways in light of a possible eggvoricity by ciliates in addition to invertebrate predation. From a study of Daphnia population during 1996 (Manca et al. 2000) it appears that a mid-June peak in eggs is not translated in a subsequent peak in adult Daphnia. This failure in the population development has characterised Daphnia's population dynamics since the lake has become oligotrophic. Because this low recruitment was coincident with an increase in the density of Bythotrephes longimanus, it was attributed to increased predation pressure by this voracious invertebrate predator. Data on demographic parameters as well as on size structure of Daphnia population agreed well with this interpretation, being the peak in mortality coincident with a depletion of small individuals, as well as with the maximum density of the predator's population.

This pattern can also be interpreted as the result of Daphnia egg consumption by ciliates and consequent pre-young mortality. The Gymnostomatid ciliate we observed in Daphnia has been identified as Lagynophrya acuminata (Fig. 2), which occurs naturally in Lago Maggiore (Callieri \& Heinimaa 1997). Analyses of samples collected weekly during June-July 1996 (Fig. 3) showed an increase of $L$. acuminata coinciding with the peak of Daphnia's eggs and the maximum density was attained shortly after.

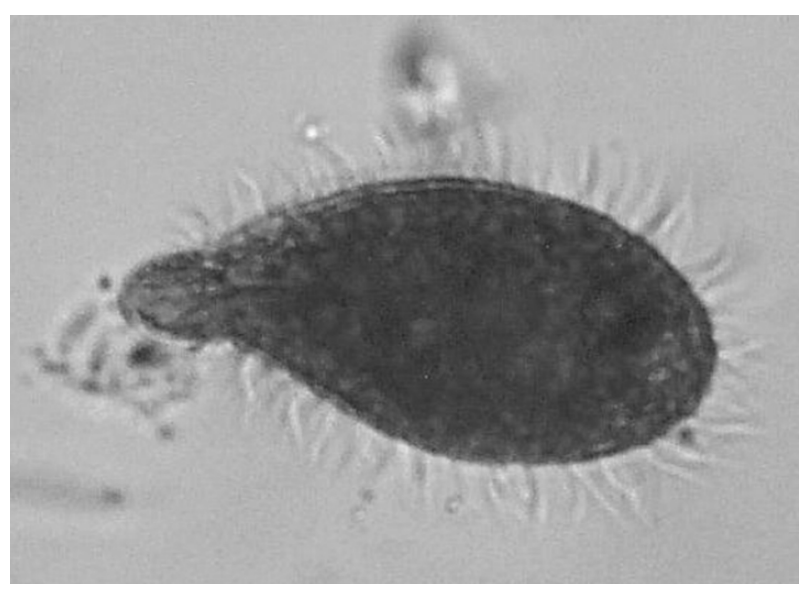

Fig. 2. Lagynophrya acuminata found in Lago Maggiore.

Gymnostomatids are known as efficient predators of flagellates and ciliates (Foissner et al. 1999), and a well studied species, Didinium nasutum, has been observed 


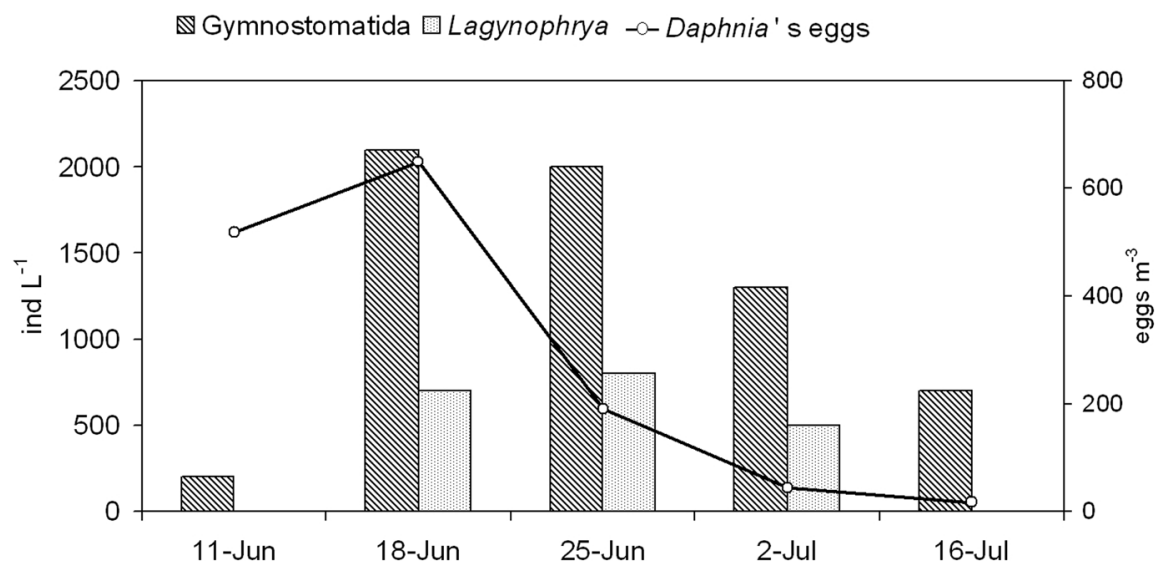

Fig. 3. Abundance of Daphnia eggs (line, right axis), of the total number of Gymnostomatids and of the number of Lagynophrya acuminata (bars, left axis) during weekly sampling of Lago Maggiore in 1996.

attacking in several individuals a single Paramecium, completely ingesting it in 2-3 minutes (Veilleux 1979). Therefore, it seems likely that Lagynophrya could attack Daphnia's eggs also in nature. An increase in the impact of ciliates on Daphnia is also consistent with the recent oligotrophication of Lago Maggiore and with the augmentation in ciliate importance in the food web observed in oligotrophic and ultra-oligotrophic lakes (Porter et al. 1988).

Consequences of ciliate eggvoricity would also resemble those brought upon by egg abortion. Egg abortion is detectable via an analysis of egg age structure, because it produces a shift towards young stages, specifically stage I (as defined by Gullbrandsen \& Johnsen, 1990), the one from which non-viable eggs are distinguishable from normal developing ones. However, egg mortality caused by ciliates, unless mostly limited to non-viable eggs, likely will not produce any alteration of the age structure of the eggs. The consumption of eggs by ciliates, if proved to be limited to non-viable ones, would provide a plausible explanation for the apparent scarcity of information on eggs or embryos' abortion in natural populations. Therefore, an analysis of literature data might reveal a link between the detection of aborted eggs and the abundance of ciliates in the plankton. Unfortunately, information on this subject is still too scanty to allow a rigorous analysis.

Any recruitment failure in cladoceran populations resulting by ciliate predation might be detected only by accurate laboratory experiments and a joint analysis of ciliate and prey population density. A re-examination of data on ciliate and cladoceran dynamics is necessary for ascertaining if our observation was only an artefact or rather a fortuitous opportunity of detecting a mechanism unrecognisable in the analysis of fixed samples.

Clearly, further research will be necessary to investigate the ecological significance of this phenomenon. In particular, it will be necessary to estimate (1) consump- tion rate by a single Lagynophrya acuminata in terms of how many Daphnia eggs are "consumed" per day; (2) its population density in the lake, (3) consumption rate (CR) by a population of $L$. acuminata over time, (4) comparing CR with the total death rate of Daphnia eggs. However, we believe that it is a very useful exercise to abandon for a moment the accepted paradigma and explore other apparently paradoxical explanations of zooplankton dynamics.

\section{ACKNOWLEDGEMENTS}

We are very indebted to R. de Bernardi and $\mathrm{J}$. Vijeverberg for their comments and suggestions, which substantially improved a previous version of the manuscript.

\section{REFERENCES}

Arndt, H. 1993. Rotifers as predators on components of the microbial web (bacteria, heterotrophic flagellates, ciliates)-a review. Arch. Hydrobiol., 8: 243-260.

Callieri, C. \& S. Heinimaa. 1997. Microbial loop in the large subalpine lakes. Mem. Ist. ital. Idrobiol., 56: 143-156.

Chatton, E. 1920. Les péridiniens parasites. Archives de Zoologie expérimentale et générale, 59: $475 \mathrm{pp}$.

Dziuban, N.A. 1939. New data on the feeding of some cyclopidae. Fish. Res. Board Canada, Transl. Ser., 418: 8 pp.

Edgerton, B.F., P. Odonoghue, M. Wingfield \& L. Owens. 1996. Systemic infection of freshwater crayfish Cherax quadricarinatus by hymenostome ciliates of the Tetrahymena pyriformis complex. Diseases of Aquatic Organisms, 27: $123-129$.

Egerter, D.E., J.R. Anderson \& J.O.Washburn. 1986. Dispersal of the parasitic ciliate Lambornella clarki: implications for ciliates in the biological-control of mosquitos. Proc. Natl. Acad. Sci. USA, 83: 7335-7339.

Fenchel, T. 1987. Ecology of Protozoa. Science Tech Publishers, Madison, Wisconsin: 197 pp.

Foissner, W., H. Berger \& J. Schaumburg. 1999. Identification and ecology of limnetic plankton ciliates. Reports Issue, 3/99 Bavarian State Office for Water Management, Munich: $200 \mathrm{pp}$. 
Gliwicz, Z.M. 1994. Retarded growth of cladoceran zooplankton in the presence of a copepod predator. Oecologia, 97: 458-461.

Gliwicz, Z.M. \& M.J. Boavida. 1996. Clutch size and body size at first reproduction in Daphnia pulicaria at different levels of food and predation. J. Plankton Res., 18: 863-880.

Gliwicz, Z.M. \& W. Lampert. 1994. Clutch size variability in Daphnia: body-size related effects of egg predation by cyclopoid copepods. Limnol. Oceanogr., 39: 479-485.

Gliwicz, Z.M. \& H. Stibor. 1993. Egg predation by copepods in Daphnia brood cavities. Oecologia, 95: 295-298.

Gliwicz, Z.M. \& G. Umana. 1996. Cladoceran body size and vulnerability to copepod predation. Limnol. Oceanogr., 39: 419-424.

Golucci, V.I. \& J.O. Corliss. 1981. A note on the occurrence of the hymenostome ciliate Tetrahymena in chironomid larvae (Diptera: Chironomida) from the Laurentian Great Lakes. Trans. Am. Microsc. Soc., 100: 89-93.

Green, J. 1974. Parasites and epibionts of Cladocera. Trans. Zool. Soc. London, 32: 515 pp.

Gullbrandsen, J. \& G.H. Johnsen. 1990. Temperature-dependent development of parthenogenetic embryos in Daphnia pulex de Geer. J. Plankton Res., 12: 443-453.

Jürgens, K. 1994. The impact of Daphnia on microbial food webs - a review. Mar. Microb. Food Webs, 8: 295-324.

Laruelle, F., D.P. Molloy, S.I. Fokin \& M.A. Ovcharenko. 1999. Histological analysis of mantle-cavity Ciliates in Dreissena polymorpha: their location, symbiotic relationship, and distinguishing morphological characteristics, New York State Museum. J. Shellfish Res., 18: 251-257.
Manca, M., C. Ramoni \& P. Comoli. 2000. The decline of Daphnia hyalina galeata in Lago Maggiore: a comparison of the population dynamics before and after oligotrophication. Aquat. Sci., 62: 142-153.

Molloy, D.P., V.A. Roitman \& J.D. Shields. 1996. Survey of the parasites of zebra mussels (Bivalvia: Dreissenidae) in Northwestern Russia, with comments on records of parasitism in Europe and North America. Journal of the Helminthological Society of Washington, 63: 251-256.

Nikolic, V.P. \& P.D. Simonovic. 1996. Occurrence of parasitic ciliate (Protozoa) on perch (Perca fluviatilis) in Lake Vlasinsko. Ann. Zool. Fenn., 33: 707-710.

Porter, K.G., H. Pearl, R. Hodson, M. Pace, J. Priscu, B. Riemann, D. Scavia \& J. Stockner. 1988. Microbial interactions in lake food webs. In: S.R. Carpenter (Ed.), Complex interactions in lake communities. Springer-Verlag, New York: 209-228.

Porter, K. 1996. Integrating the microbial loop and the classic food chain into a realistic food web.. In: G. Polis and K. Winemiller (Eds), Food webs integration of pattern and dynamics. Chapman and Hall: 51-59.

Sanders, R.W. \& S.A. Wickham. 1993. Planktonic protozoa and metazoa: predation, food quality and population control. Mar. Microb. Food Web, 7: 197-223.

Stoecker, D.K. \& J.M. Capuzzo. 1990. Predation on protozoa: its importance to zooplankton. J. Plankton Res., 12: 891908.

Veilleux, B.G. 1979. An analysis of the predatory interaction between Paramecium and Didinium. J. Anim. Ecol., 48: 798-803. 